\title{
Clinical and Molecular Findings in Mendelian Susceptibility to Mycobacterial Diseases: Experience From India
}

\section{OPEN ACCESS}

Edited by:

Sudhir Gupta,

University of California, Irvine,

United States

Reviewed by:

Sergio Rosenzweig,

National Institutes of Health $(\mathrm{NIH})$,

United States

Hamoud Al-Mousa

King Faisal Specialist Hospital \&

Research Centre, Saudi Arabia

*Correspondence:

Mukesh M. Desai

mmdesai007@gmail.com

Specialty section:

This article was submitted to

Primary Immunodeficiencies,

a section of the journal

Frontiers in Immunology

Received: 19 November 2020 Accepted: 02 February 2021

Published: 25 February 2021

Citation:

Taur PD, Gowri V, Pandrowala AA, lyengar W, Chougule A, Golwala Z,

Chandak S, Agarwal R, Keni P,

Dighe N, Bodhanwala M, Prabhu S,

George B, Fouzia NA, Edison ES,

Arunachalam AK, Madkaikar MR,

Dalvi AD, Yadav RM, Bargir UA, Kambli PM, Rawat A, Das J, Joshi V,

Pilania RK, Jindal AK, Bhat $S$, Bhattad S, Unni J, Radhakrishnan N,

Raj R, Uppuluri R, Patel $S$,

Lashkari HP, Aggarwal A, Kalra M,

Udwadia Z, Bafna VS, Kanade T,

Puel A, Bustamante J, Casanova JL and Desai MM (2021) Clinical and

Molecular Findings in Mendelian

Susceptibility to Mycobacterial

Diseases: Experience From India.

Front. Immunol. 12:631298.

doi: 10.3389/fimmu.2021.631298
Prasad D. Taur ${ }^{1}$, Vijaya Gowri ${ }^{1}$, Ambreen Abdulwahab Pandrowala ${ }^{1}$, Vaishnavi V. lyengar ${ }^{1}$, Akshaya Chougule ${ }^{1}$, Zainab Golwala ${ }^{1}$, Shraddha Chandak ${ }^{1}$, Reepa Agarwal ${ }^{1}$, Purva Keni ${ }^{1}$, Neha Dighe ${ }^{1}$, Minnie Bodhanwala ${ }^{1}$, Shakuntala Prabhu ${ }^{1}$, Biju George $^{2}$, N. A. Fouzia ${ }^{2}$, Eunice Sindhuvi Edison ${ }^{2}$, Arun Kumar Arunachalam², Manisha Rajan Madkaikar ${ }^{3}$, Aparna Dhondi Dalvi ${ }^{3}$, Reetika Malik Yadav ${ }^{3}$, Umair Ahmed Bargir ${ }^{3}$, Priyanka Madhav Kambli ${ }^{3}$, Amit Rawat ${ }^{4}$, Jhumki Das ${ }^{4}$, Vibhu Joshi ${ }^{4}$, Rakesh Kumar Pilania ${ }^{4}$, Ankur Kumar Jindal ${ }^{4}$, Sunil Bhat ${ }^{5}$, Sagar Bhattad ${ }^{6}$, Jeeson Unni ${ }^{6}$, Nita Radhakrishnan ${ }^{7}$, Revathi Raj ${ }^{8}$, Ramya Uppuluri ${ }^{8}$, Shivani Patel ${ }^{8}$, Harsha Prasada Lashkari ${ }^{9}$, Amita Aggarwal ${ }^{10}$, Manas Kalra ${ }^{11}$, Zarir Udwadia ${ }^{12}$, Vibha Sanjay Bafna ${ }^{13}$, Tarun Kanade ${ }^{14}$, Anne Puel ${ }^{15,16,17}$, Jacinta Bustamante ${ }^{15,16,17,18}$, Jean Laurent Casanova ${ }^{15,16,17,19}$ and Mukesh M. Desai ${ }^{1 *}$

${ }^{1}$ Department of Immunology, B. J. Wadia Hospital for Children, Mumbai, India, ${ }^{2}$ Department of Clinical Hematology, Christian Medical College, Vellore, India, ${ }^{3}$ Indian Council of Medical Research-National Institute of Immunohematology, Mumbai, India, ${ }^{4}$ Department of Pediatrics, Advanced Pediatrics Centre, Post Graduate Institute of Medical Education and Research, Chandigarh, India, ${ }^{5}$ Mazumdar Shaw Cancer Centre, Narayana Health City, Bengaluru, India, ${ }^{6}$ ASTER CMI Hospitals, Bengaluru, India, ${ }^{7}$ Superspeciality Hospital, Noida, India, ${ }^{8}$ Apollo Hospitals, Chennai, India, ${ }^{9}$ Kasturba Medical College and Hospital, Mangalore, India, ${ }^{10}$ Department of Clinical Immunology and Rheumatology, Sanjay Gandhi Post Graduate Institute of Medical Sciences, Lucknow, India, ${ }^{11}$ Sir Ganga Ram Hospital, New Delhi, India, ${ }^{12}$ Hinduja Hospital, Mumbai, India,

${ }^{13}$ Bharati Hospital, Pune, India, ${ }^{14}$ Rainbow Safalya Hospital, Nashik, India, ${ }^{15}$ University of Paris, Institute Imagine, INSERM, Paris, France, ${ }^{16}$ Laboratory of Human Genetics of Infectious Diseases, Necker Branch, INSERM UMR1163, Paris, France, ${ }^{17}$ St. Giles Laboratory of Human Genetics of Infectious Diseases, Rockefeller Branch, The Rockefeller University, New York, NY, United States, ${ }^{18}$ Study Center for Immunodeficiencies, Necker Hospital for Sick Children, AP-HP, Paris, France,

${ }^{19}$ Howard Hughes Medical Institute, New York, NY, United States

Mendelian Susceptibility to Mycobacterial diseases (MSMD) are a group of innate immune defects with more than 17 genes and 32 clinical phenotypes identified. Defects in the IFN- $\gamma$ mediated immunity lead to an increased susceptibility to intracellular pathogens like mycobacteria including attenuated Mycobacterium bovis-Bacillus Calmette-Guérin (BCG) vaccine strains and non-tuberculous environmental mycobacteria (NTM), Salmonella, fungi, parasites like Leishmania and some viruses, in otherwise healthy individuals. Mutations in the $I L 12 R B 1$ gene are the commonest genetic defects identified. This retrospective study reports the clinical, immunological, and molecular characteristics of a cohort of 55 MSMD patients from 10 centers across India. Mycobacterial infection was confirmed by GeneXpert, Histopathology, and acid fast bacilli staining. Immunological workup included lymphocyte subset analysis, Nitro blue tetrazolium (NBT) test, immunoglobulin levels, and flow-cytometric evaluation of the IFN- $\gamma$ mediated immunity. Genetic analysis was done by next generation sequencing (NGS). Disseminated BCG-osis was the commonest presenting manifestation (82\%) with a median age of presentation of 6 months due to the practice of BCG vaccination at birth. This was followed by infection with Salmonella and non-typhi Salmonella (13\%), Cytomegalovirus (CMV) (11\%), Candida (7\%), NTM (4\%), and Histoplasma (2\%). 
Thirty-six percent of patients in cohort were infected by more than one organism. This study is the largest cohort of MSMD patients reported from India to the best of our knowledge and we highlight the importance of work up for IL-12/IL-23/ISG15/IFN- $\gamma$ circuit in all patients with BCG-osis and suspected MSMD irrespective of age.

Keywords: IL-12/IL-23/ISG15/IFN- $\gamma$ axis, intracellular pathogens, BCG-osis, Mycobacterium tuberculosis complex, IL-12R $\beta 1$ defect, anti-tubercular treatment

\section{INTRODUCTION}

Mendelian Susceptibility to Mycobacterial diseases (MSMD) now also known as Inborn Errors of IFN- $\gamma$ immunity (IEI) are a group of innate or intrinsic immune defects localized to 17 genes and 32 clinical phenotypes identified (1-3). IL$12 / 23$ /ISG15-IFN- $\gamma$ axis is the principal immunological pathway for intra-macrophagic pathogens $(4,5)$. Defects in this pathway lead to an increased susceptibility to intracellular pathogens like mycobacteria including attenuated Mycobacterium bovisBacillus Calmette-Guérin (BCG) vaccine strains and nontuberculous environmental mycobacteria (EM), Salmonella, fungi, parasites like Leishmania, and some viruses, in otherwise healthy individuals $(4,6-9)$. Tuberculosis is the commonest public health problem in India with an estimated incidence of 2.4 million cases in 2019 (10). BCG vaccination is universally administered to all babies soon after birth (11), to protect against severe forms of tuberculosis. Adverse event following BCG immunization might be the presenting manifestation in MSMD.

In a setting of strong clinical suspicion, flow-cytometric evaluation of IL-12/23-IFN- $\gamma$ pathway followed by molecular work-up for identifying the genetic etiology is warranted. Our first patient of IL-12R $\beta 1$ defect was diagnosed with help from Dr. Dinakantha Kumararatne from Cambridge. Subsequently, our initial cases suspected with MSMD were evaluated by Dr. Jacinta Bustamante and Pr. Jean-Laurent Casanova at Paris; and a genetic cause could be identified in nine patients with three IL-12R $\beta 1$ complete defects, two IFN- $\gamma \mathrm{R} 1$ (partial dominant), two STAT1 (partial dominant, loss-of-function), one complete IFN- $\gamma$ R1 defect, and one complete IL-12p40 defect. In India, with increasing awareness about MSMD, pediatricians, infectious disease specialists, hemato-oncologists and those dealing with the menace of Mycobacterium tuberculosis (M. $t b$ ) started recognizing and appreciating genetic factors responsible for susceptibility to mycobacterial tuberculosis. With the ease of access to next generation sequencing (NGS) in recent years, the diagnosis of MSMD has increased.

There is a paucity of literature on MSMD from India with only a few published case reports (12-15). In this study, we report clinical, immunological, and molecular characteristics of a retrospective cohort of 55 MSMD patients from 10 centers across India.

\section{MATERIALS AND METHODS}

Ten participating of Primary immunodeficiencies (PID) centers from India contributed data for this retrospective analysis. The participating centers included Bai Jerbai Wadia Hospital for
Children, Mumbai $(n=14)$, Christian Medical College; Vellore $(n=11)$, Indian Council of Medical Research-National Institute Immunohaematology; Mumbai $(n=10)$, ACPED (Advance Center for Pediatrics) PGI, Chandigarh $(n=8)$, ASTER CMI; Bangalore $(n=3)$, Narayana Hrudayalaya; Bangalore $(n=3)$, Kasturba Medical College and Hospital; Mangalore $(n=2)$, Apollo Hospital; Chennai $(n=2)$, Superspeciality Pediatric Hospital and Post Graduate Teaching Institute; Noida $(n=1)$, and Sir Ganga Ram Hospital, Delhi $(n=1)$. All centers were contacted via email and requested to provide details of their MSMD patients on a pre-designed Microsoft Excel datasheet. Details included demographic information, clinical manifestations, family history, microbiological and immunological investigations, genetic evaluation, management, and follow-up. Being a retrospective analysis of data, it was exempted from ethics approval.

Diagnosis of infection with Mycobacterium tuberculosis complex (MTBC) was confirmed by PCR in addition to histopathologic and microbiologic findings of acid-fast bacilli (AFB) detected from lymph nodes or broncho-alveolar lavage. Diagnostic approach for suspected MSMD included basic lymphocyte subset analysis, nitroblue tetrazolium (NBT) test, immunoglobulin levels, and flow-cytometric evaluation of the IFN- $\gamma$ R1 (CD119), IL-12R $\beta 1$ (CD212), serum IFN- $\gamma$ levels, STAT1, and STAT4 phosphorylation along with NGS for making a molecular diagnosis. NGS included PID targeted-gene panel and clinical Exome sequencing. Imaging studies including chest $\mathrm{X}$-ray, ultrasound, and chest CT scan were used when internal organ involvement was suspected. The specialized assays were used for rapid identification of the candidate gene when molecular facilities were not freely available initially. Eventually with the easy availability of NGS facilities, the relevant assays were performed for functional validation of the identified mutation and has been carried out in majority of the cases. Some centers performed molecular workup directly after the basic immune work-up for the patients suspected with MSMD.

Statistical analysis of data was obtained on a predesigned worksheet (Excel, Microsoft Office) and analyzed using Graph pad Prism (Chicago, IL, USA) for Microsoft Windows. Kaplan Meier's analysis was used to estimate the risk of BCG related complications.

\section{RESULTS}

\section{Patient Characteristics}

In this study, we analyzed a total of 55 patients of MSMD of which 51 (93\%) had a confirmed molecular diagnosis and four were evaluated by flow cytometry. The clinical and demographic 
TABLE 1 | Demographic and clinical findings.

\begin{tabular}{|c|c|c|c|c|c|c|c|c|c|}
\hline Patient ID & $\begin{array}{l}\text { Age of } \\
\text { presentation } \\
\text { (in months) }\end{array}$ & Sex & Consanguinity & $\begin{array}{l}\text { Family } \\
\text { history }\end{array}$ & BCGosis & Salmonella & $\begin{array}{l}\text { Other } \\
\text { organisms }\end{array}$ & $\begin{array}{l}\text { Type of MSMD } \\
\text { Defect }\end{array}$ & Outcome \\
\hline P2 & 6 & $\mathrm{~F}$ & - & - & + & - & $\begin{array}{l}\text { Pseudomonas } \\
\text { aeruginosa, } \\
\text { CMV }\end{array}$ & $\mid F N-\gamma R 1$ & A \\
\hline P5 & 3 & $\mathrm{~F}$ & + & + & + & - & - & STAT1 & $\mathrm{D}$ \\
\hline P6 & 11 & M & + & - & + & - & - & IFN- $\gamma R 2$ & $A$ \\
\hline P7 & 168 & M & + & + & + & - & $\begin{array}{l}\text { Giardia, } \\
\text { Histoplasma }\end{array}$ & $\| L-12 R \beta 1$ & A \\
\hline P8 & 120 & M & - & + & + & + & - & $\|-12 R \beta 1$ & A \\
\hline P12 & 24 & M & + & + & + & - & - & $\mid F N-\gamma R 1$ & $\mathrm{D}$ \\
\hline P13 & 180 & M & + & - & - & - & $\begin{array}{l}\text { Mycobacterium } \\
\text { leprae }\end{array}$ & $\mid F N \gamma R 1$ & $\mathrm{D}$ \\
\hline P14 & 9 & $\mathrm{~F}$ & - & - & + & - & - & $\| L-12 R \beta 1$ & A \\
\hline P15 & 27 & $\mathrm{~F}$ & - & - & + & - & - & $I L-12 R \beta 1$ & Lost F/U \\
\hline P16 & 48 & M & - & - & + & - & Candida & $\| L-12 R \beta 1$ & Lost F/U \\
\hline P17 & 12 & $\mathrm{~F}$ & + & + & + & - & - & $\mid L-12 R \beta 1$ & A \\
\hline P18 & 3 & $\mathrm{~F}$ & + & + & + & - & - & $\| L-12 R \beta 1$ & $\mathrm{D}$ \\
\hline P19 & 132 & M & + & - & + & - & - & $\|-12 R \beta 1$ & $A$ \\
\hline P27 & 72 & $\mathrm{~F}$ & - & - & + & - & Varicella Zoster & $I F N \gamma R 1$ & $A$ \\
\hline P28 & 4 & $\mathrm{~F}$ & + & + & + & - & - & $\|-12 R \beta 1$ & $A$ \\
\hline P29 & 3 & M & + & + & + & - & - & IFN- $\gamma R 2$ & $\mathrm{D}$ \\
\hline P30 & 6 & M & - & + & + & - & - & STAT1 & $A$ \\
\hline P31 & 6 & M & & - & + & - & - & $I F N \gamma R 1$ & Lost F/U \\
\hline P32 & 7 & $\mathrm{~F}$ & + & - & + & + & - & $\mid L-12 R \beta 1$ & A \\
\hline P33 & 4 & M & - & - & + & - & - & $\mid L-12 R \beta 1$ & A \\
\hline P34 & 2 & $\mathrm{~F}$ & - & - & + & - & - & $\| L-12 R \beta 1$ & Lost F/U \\
\hline P35 & 13 & M & + & - & + & - & CMV, NTM & $\mid F N-\gamma R 1$ & A \\
\hline P36 & 3 & M & + & - & + & - & - & $\| L-12 R \beta 1$ & A \\
\hline P37 & 3 & M & + & - & + & - & $\begin{array}{l}\text { Streptococcus } \\
\text { pneumoniae, } \\
\text { Enterococcus, } \\
\text { BOCA VIRUS }\end{array}$ & ISG15 & $\mathrm{D}$ \\
\hline P38 & 3 & M & - & - & + & - & - & IFN- $\gamma R 2$ & $\mathrm{D}$ \\
\hline P39 & 4 & $\mathrm{~F}$ & - & + & - & + & - & $\mid L-12 R \beta 1$ & A \\
\hline P40 & 1 & $\mathrm{~F}$ & - & - & + & - & $\begin{array}{l}\text { Staphylococcus } \\
\text { aureus }\end{array}$ & $\mid L-12 R \beta 1$ & A \\
\hline
\end{tabular}


TABLE 1 | Continued

\begin{tabular}{|c|c|c|c|c|c|c|c|c|c|}
\hline Patient ID & $\begin{array}{l}\text { Age of } \\
\text { presentation } \\
\text { (in months) }\end{array}$ & Sex & Consanguinity & $\begin{array}{l}\text { Family } \\
\text { history }\end{array}$ & BCGosis & Salmonella & $\begin{array}{l}\text { Other } \\
\text { organisms }\end{array}$ & $\begin{array}{l}\text { Type of MSMD } \\
\text { Defect }\end{array}$ & Outcome \\
\hline P41 & 1 & $M$ & - & - & + & - & - & $I L-12 R \beta 1$ & D \\
\hline P42 & 1 & $M$ & - & - & - & - & - & STAT1 & $A$ \\
\hline P43 & 7 & $M$ & - & + & + & - & - & $I F N-\gamma R 2$ & Lost F/U \\
\hline P44 & 48 & $\mathrm{M}$ & - & - & + & + & - & $\mid F N-\gamma R 1$ & Lost F/U \\
\hline P45 & 120 & $\mathrm{~F}$ & - & - & - & + & Proteus & $I L-12 R \beta 1$ & Lost F/U \\
\hline P46 & 120 & $\mathrm{M}$ & - & + & + & + & $\begin{array}{l}\text { Clostridium } \\
\text { difficile }\end{array}$ & $\mid L-12 R \beta 1$ & Lost F/U \\
\hline P47 & 96 & $\mathrm{M}$ & - & - & + & - & - & $I F N \gamma R 1$ & Lost F/U \\
\hline P48 & 36 & $\mathrm{~F}$ & + & - & + & - & $\begin{array}{l}\text { Streptococcus } \\
\text { pyogenes }\end{array}$ & $\mid F N \gamma R 1$ & Lost F/U \\
\hline P49 & 6 & $\mathrm{~F}$ & + & + & + & - & - & $I L-12 R \beta 1$ & Lost F/U \\
\hline P50 & 6 & $M$ & - & + & + & - & - & $I L-12 R \beta 1$ & Lost F/U \\
\hline P51 & 9 & $\mathrm{M}$ & + & + & - & - & $C M V$ & $I F N-\gamma R 2$ & A \\
\hline P52 & 6 & $M$ & + & + & - & - & Neisseria, CMV & $I F N-\gamma R 2$ & D \\
\hline P53 & 6 & $\mathrm{M}$ & + & - & - & - & Candida & $I L-12 R \beta 1$ & A \\
\hline P54 & 3 & $\mathrm{M}$ & - & - & + & - & $C M V$ & $\mid F N-\gamma R 1$ & A \\
\hline P55 & 60 & $M$ & - & - & - & - & - & $I L-12 R \beta 1$ & $A$ \\
\hline
\end{tabular}

$D$, dead; $A$, alive; $F / U$, follow-up.

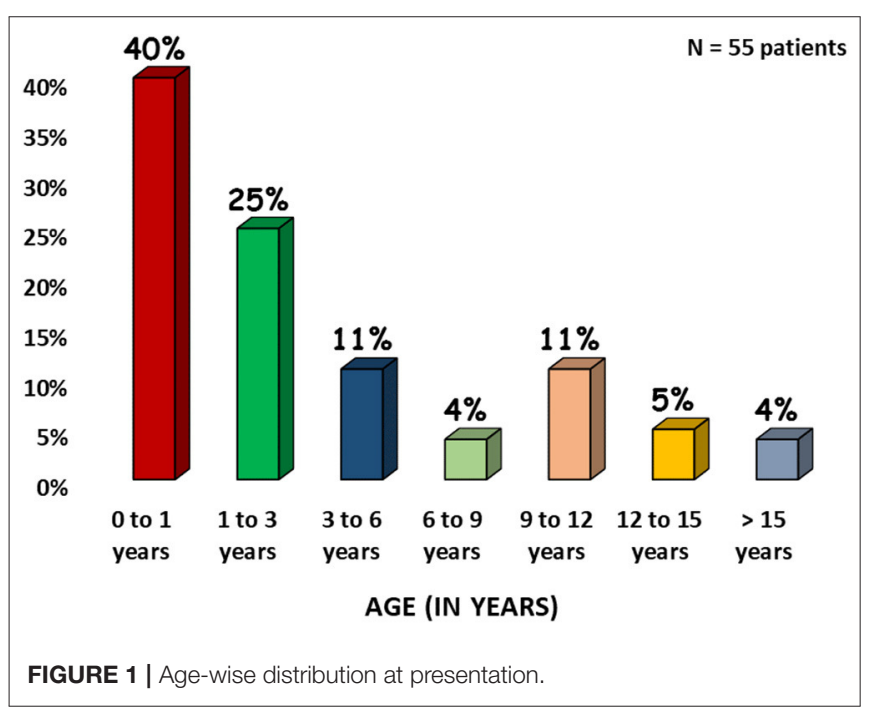

details of the patients are presented in Table 1. There was a slight male preponderance with $56 \%$ males and $44 \%$ females. History of consanguinity was present in 58\% families and 33\% families had history of a previous affected sibling. The median age of presentation was 6 months ( $0.5-300$ months). Figure 1 shows the age-wise distribution at presentation.

The commonest clinical presentation was disseminated BCGosis (82\% patients) [ESID criteria for BCG-itis and BCG-osis was followed (16)], representative clinical images are shown in Figure 2. The average number of organs involved in patients with BCG-osis was three.

\section{Microbiological Spectrum}

All patients in the cohort had mycobacterial disease with MTBC (96\%), and non-tuberculous mycobacteria (NTM) in (4\%). Multisystem involvement with mycobacteria was the commonest followed by lymph node involvement, tubercular osteomyelitis, pulmonary, skin, and central nervous system (CNS) in the order of decreasing frequency (Figure 3 ).

Thirty-six percent of patients in cohort were infected by more than one organism. Other infections associated with our cohort were Salmonella and non-typhi Salmonella (13\%), Candida (7\%), Histoplasma (2\%), Nocardia (2\%), Mycobacterium leprae (2\%) other bacterial infections like Staphylococcus aureus (4\%), Streptococci (4\%), Pseudomonas aeruginosa (2\%), Neisseria (2\%), Proteus mirabilis (2\%), Clostridium difficile (2\%), Enterococci (4\%), and viruses Cytomegalovirus (CMV, 11\%), Molluscum (2\%), Varicella zoster (2\%), Bocavirus (2\%). The overall microbiological spectrum and distribution of infections with different families of micro-organisms are presented in Figure 4.

\section{Immunological and Molecular Evaluation}

Evaluation of the IL-12/23/IFN- $\gamma$ pathway by flow-cytometry could be performed in 21 patients and the results were consistent with the underlying molecular defect. NGS analysis in 55 MSMD patients within 51 families led to the identification of 5 previously reported and 24 novel mutations in 7 different genes as presented in Table 2. The pathogenicity of novel mutations identified in our cohort was determined by in silico tools like Mutation Taster, SIFT and Polyphen-2, and genotype-phenotype correlation.

The spectrum of molecular defects identified in the patients is presented in Figure 5. The prevalence of different molecular defects in India is consistent with world literature as shown in Figure $5(21,22)$. 


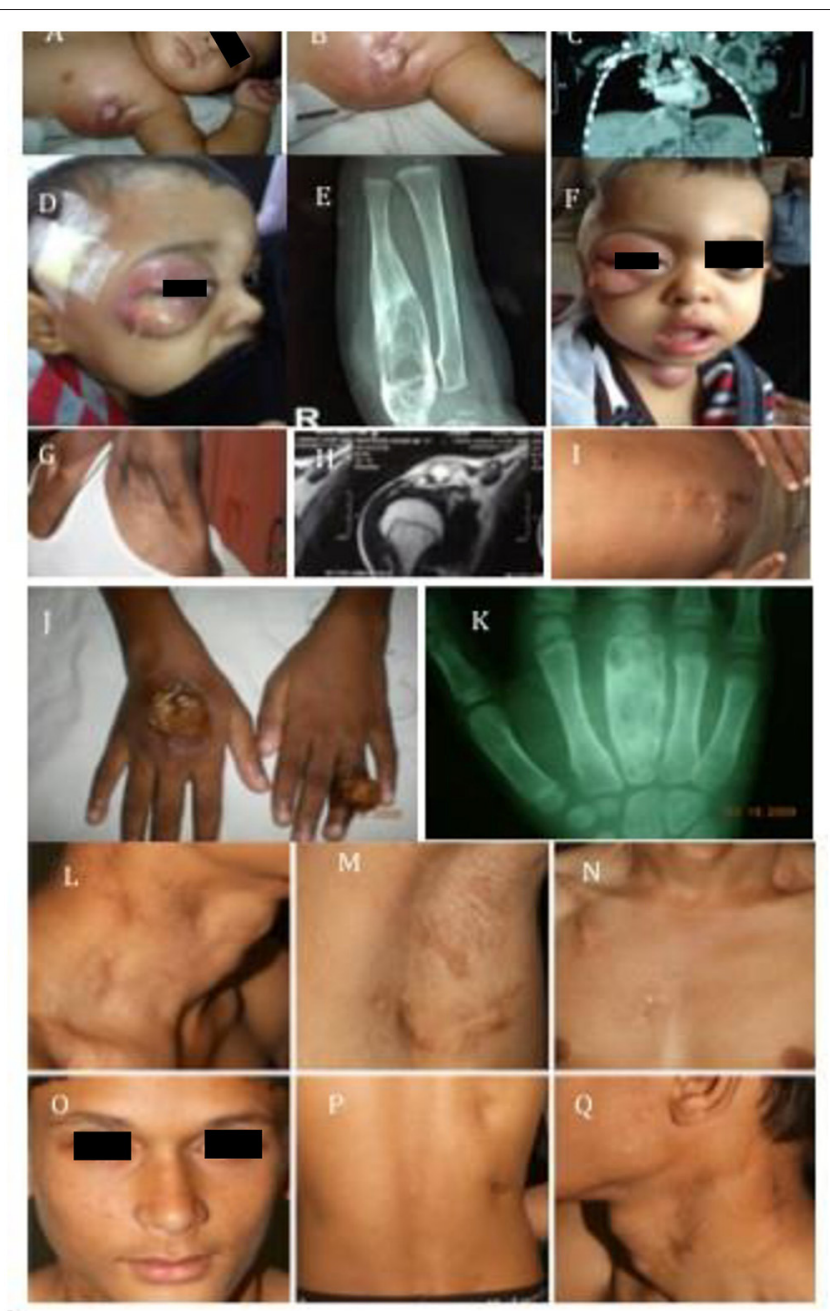

FIGURE 2 | Clinical images. (A-C) Show image of BCG-osis without failure to thrive: IL-12R $\beta 1$ defect. (D-F,J,K) Represent multi-focal bone involvement seen in PD-IFN $\gamma$ R1 defect or AD-STAT1 defect. (G-I) Shows child with BCG-osis, shoulder, and disseminated Histoplasmosis: IL-12R $\beta 1$ defect.

(L-Q) Represent another case of BCG-osis with impetigo and

lymphadenopathy whose culture grew non-typhi Salmonella: IL-12R $\beta 1$ defect.

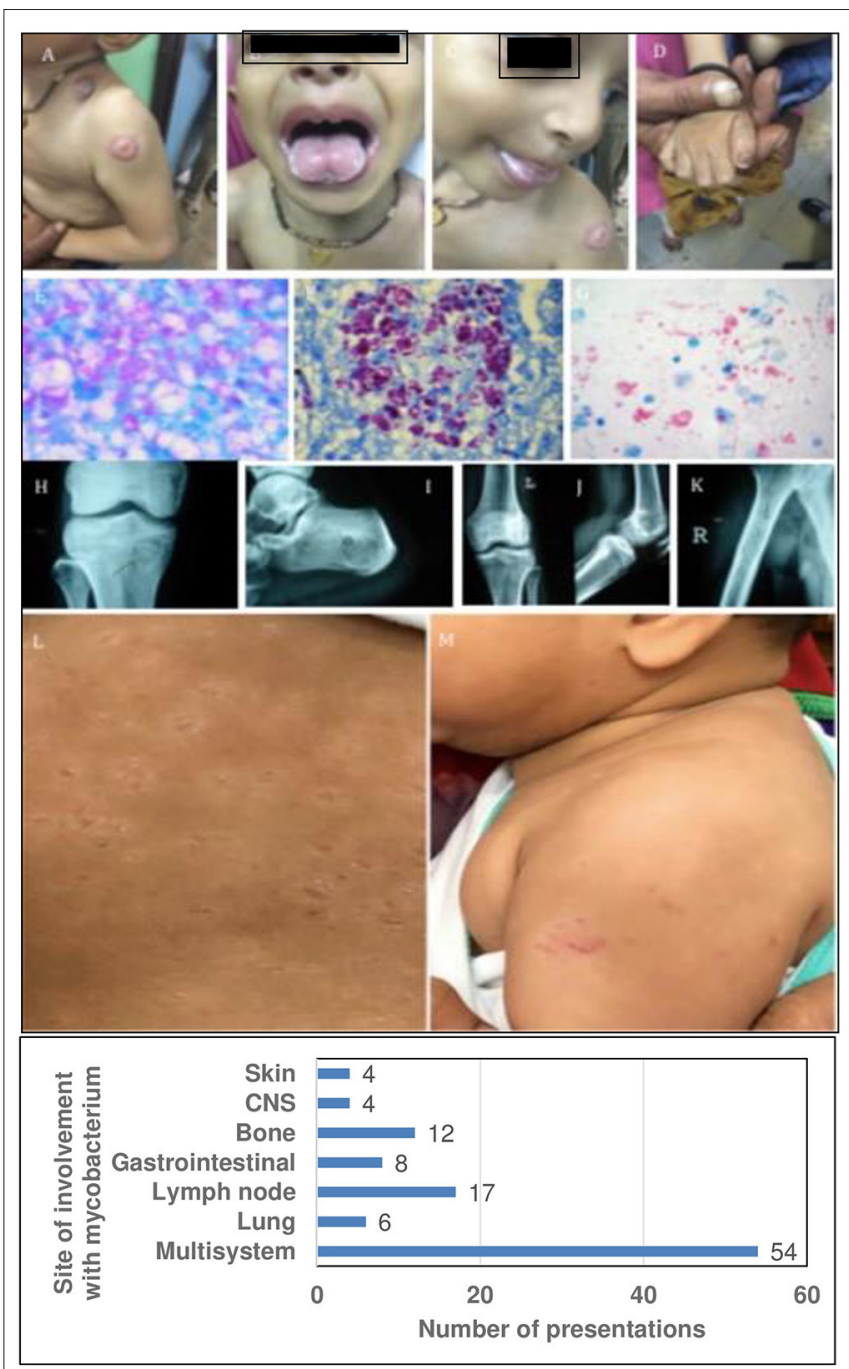

$\mathrm{N}$

FIGURE 3 | Representative clinical images and sites of involvement of Mycobacteria. (A-D) Show BCG-osis with candidiasis: IL-12R $\beta 1$ defect or ROR- $\gamma \top$ defect. (E-G) Show exuberant growth of AFB in tissue Liver Biopsy (F) also shows CMV inclusions. (H-K) multifocal bone TB: IFN- $\gamma R 1$ or IFN- $\gamma$ R2 defect. (L,M) Show cutaneous BCG-osis. (N) Showing graph with sites of involvement with mycobacterium.

\section{AR Complete IL-12R $\beta 1$ Deficiency}

The complete IL-12R $\beta 1$ defect was identified in 25 patients presenting at a median age of presentation of 9 months (Range 1-300 months). 21/25 (84\%) patients presented with BCG-osis; Six patients (P8, P9, P32, P39, P45, and P46) had recurrent Salmonella infection and three patients (P10, P16, and P53) had Candidiasis along with tuberculosis. Nineteen patients (76\%) had only BCG-osis and did not develop any other infections during the period of follow up. Autoimmune manifestations in the form of inflammatory bowel disease was seen in three patients (P8, P45, and P46) and one patient (P46) had autoimmune hemolytic anemia, leukocytoclastic vasculitis and was ANA positive. The other infections identified included Histoplasma (P7), Giardia (P7), Staphylococcus (P40), Proteus (P45), Enterococcus (P45), and Clostridium difficile (P46). One patient (P7) with histoplasmosis and BCG-osis also had CD4 lymphopenia and portal vein thrombosis. Consanguinity was present in 12/25(48\%) patients and there was history of a previous affected sibling in 7/25(28\%) families. Flow cytometric evaluation of IL-12R $\beta 1$ expression was found to be absent in 11 patients where it was evaluated.

IL-12R $\beta 1$ was the predominant gene affected in our cohort with a homozygous mutation located in exon 9, c.962C $>\mathrm{A}$ being the commonest mutation identified (11/25) followed by another mutation Intron $15 \mathrm{c} .1791+2 \mathrm{~T}>\mathrm{G}(6 / 25)$. Two of our patients had homozygous missense mutation in exon 16 of IL12R $\beta 1$, c. $1786 \mathrm{~A}>\mathrm{G}$. This mutation was reported as benign in Clinvar, however flow cytometry confirmed deficient $I L-12 R \beta 1$. 


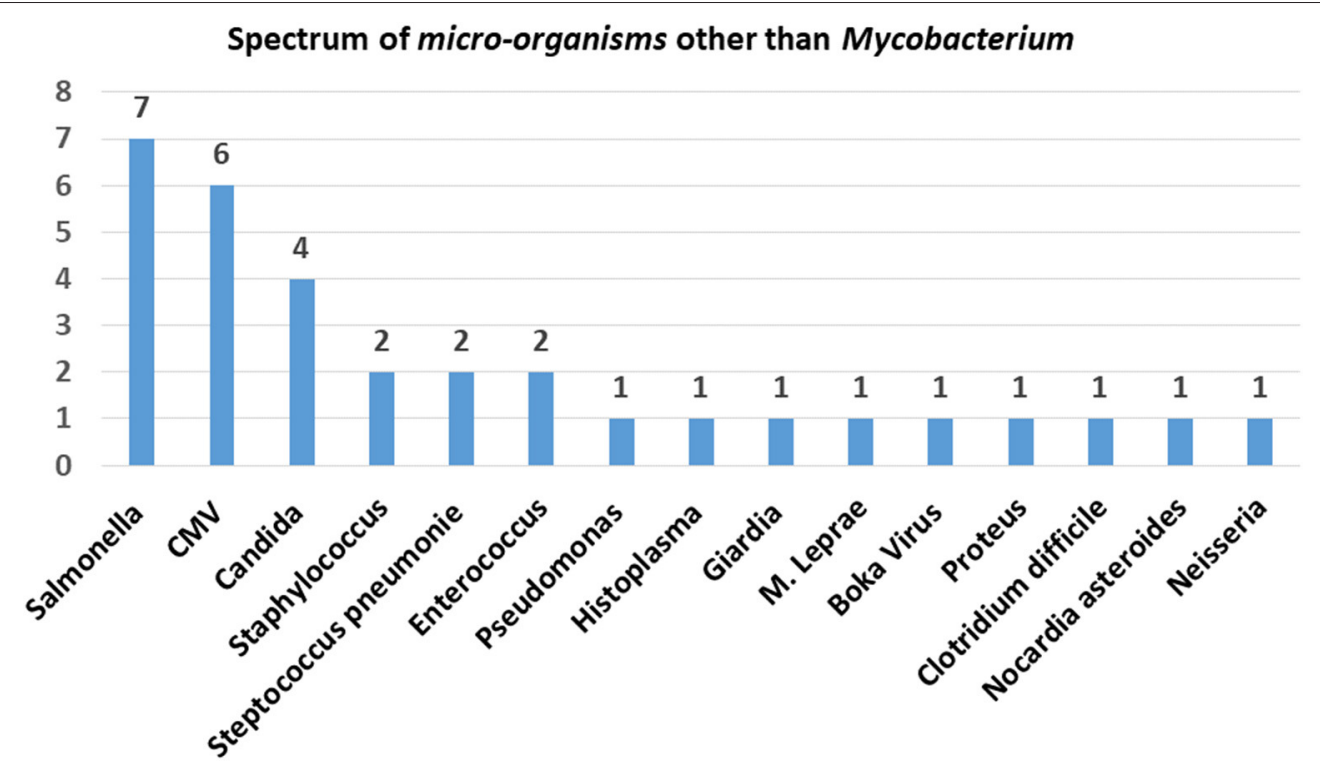

FIGURE 4 | Microbiological spectrum.

Carrier status in parents was confirmed in three families. All patients received anti-mycobacterial treatment with antibiotics. Two siblings also had an aspiration of pus for BCG-itis. Three patients of complete IL-12R $\beta 1$ deficiency (P32, P53, and P55) underwent allogeneic hematopoietic stem cell transplantation (HSCT), which engrafted well and the patients are doing well. P32 and P53 had father as haploidentical donor while P55 had a fully matched sibling donor. Four (16\%) patients (P10, P18, P25, and P41) expired.

Three of our patients developed inflammatory bowel disease (IBD) during follow up which is not reported in world literature. IL-12R $\beta 1$ defect also results in TH17 pathway defect that can be associated with autoimmunity and auto inflammation which could be the cause of IBD in our patients. This needs to be investigated further.

\section{AR Complete IL-12p40 Deficiency}

IL-12p40 defect was identified in one patient (P3) who presented at three months of age with BCG-osis and also needed admission twice due to tubercular pleural effusion. The patient received ATT thrice and is doing well.

\section{AR Complete IFN- $\gamma$ R1 Deficiency}

Complete IFN- $\gamma$ R1 deficiency was identified in eight patients. The median age of presentation was 5.5 months (0.5-36 months). BCG-osis was the presenting manifestation in all patients. Additional infections with Streptococcus (P48), and CMV (P1, P35, and P54) were observed. Flow cytometric evaluation of IFN$\gamma \mathrm{R} 1$ was performed in four patients and found to be absent in three. One patient (P1) revealed a partial expression, however, baseline IFN- $\gamma$ levels were very high and downstream STAT1 phosphorylation was found to be absent suggesting that although partial expression of IFN- $\gamma \mathrm{R} 1$ was present, it was non-functional. All patients received ATT for mycobacterial infections. Two
(25\%) patients (P1 and P12) expired due to respiratory distress and hypersplenism with increased transfusion requirement. One patient (P54) with complete IFN- $\gamma \mathrm{R} 1$ underwent haploidentical HSCT as the child had no matched family donor, nor any matched unrelated donor. He rejected his graft and had autologous reconstitution by day 28 post-HSCT. He continues to be on four ATT drugs. One patient (P35) is well on ATT and NTM prophylaxis. Four patients are (P21, P22, P31, and P48) are lost to follow up.

\section{AD Partial IFN- $\gamma$ R1 Deficiency}

Seven patients were diagnosed with a partial dominant (PD) IFN- $\gamma$ R1 deficiency with a median age of presentation of 72 months (4-180 months). BCG-osis was the presenting manifestation in 6/7(86\%) patients. Severe forms of the disease in the form of multifocal osteomyelitis were identified in $(71 \%)$ five patients (P2, P11, P13, P44, and P47) with PD IFN- $\gamma$ R1 defect which was similar to world literature (21). The organisms isolated included tubercular and non-tubercular mycobacteria. One patient (P11) also identified with PD IFN- $\gamma$ R1defect had recurrent lymphadenopathy and joint involvement and extensive cutaneous infection with Mycobacterium avium intracellulare (Figure 6). She also developed molluscum contagiosum of the vulvar region. Other infections associated with partial dominant defect were Pseudomonas aeruginosa (P2), Staphylococcus aureus (P11), Mycobacterium leprae (P13), Salmonella (P44), CMV (P2) leading to secondary hemophagocytic lymphohistiocytosis (HLH), and Varicella (P27). Flow cytometry was performed in all seven patients, and showed increased IFN- $\gamma$ R1 expression, and abnormal STAT1 phosphorylation suggestive of the PD IFN- $\gamma$ R1 deficiency. All four patients in whom mutation was available had c.818_821delTTAA in exon 6 of IFNGR1. All patients received anti-tubercular treatment for mycobacterial 
infections. P27 needed three courses of ATT for recurrent lymphadenopathy. Two patients (P2 and P13) expired while two patients (P44 and P47) are lost to follow up. Rest three patients (P11, P23, and P27) are alive and doing well.

\section{AR Complete IFN- $\gamma$ R2 Deficiency}

IFN- $\gamma$ R2 deficiency was identified in eight patients (14\%) which is higher than $3 \%$ reported in world literature (21). The median age of presentation is 6.5 months (3-14 months). All vaccinated patients presented with BCG-osis; two patients were not vaccinated due to previous affected sibling. One patient ( $\mathrm{P} 43$ ) had a previously affected siblings, he had recurrent mycobacterial infection and needed three courses of ATT. Other infections identified included CMV infection in P51 and P52 and Neisseria in P52; both were siblings. Consanguinity was identified in $6 / 8$ (75\%) families. Three (37.5\%) patients (P24, P29, and P38) expired before transplant. The siblings P51 and P52 underwent haplo-identical transplant; P51 is alive and well, while P52 expired 2 years later due to an unrelated cause.

\section{STAT1 Deficiency}

STAT1 deficiency was identified in four patients of whom two patients had an AR complete defect (P4 and P5) and two had a PD partial defect (P30 and P42). Both patients with a complete defect and one with a partial defect (P30) presented with BCG-osis and one patient with partial defect (P42) had history of recurrent tuberculosis. No other infections besides MTBC were identified in any patients. Both patients with complete defect were siblings and born of a consanguineous marriage. One patient with a partial defect (P30) had family history of father affected with cutaneous tuberculosis and paternal grandmother affected with Pott's spine, suggestive of autosomal dominant transmission. STAT1 phosphorylation by flow cytometry was found to be absent in both patients with complete STAT1 defect who were evaluated along with normal IFN- $\gamma$ levels. Both patients with complete defect expired, one patient with PD defect (P42) is on antibiotic prophylaxis for recurrent respiratory tract infections and the other is on anti-mycobacterial treatment.

\section{ISG15 Defect}

One patient (P37) was identified with ISG15 defect, born of a third-degree consanguineous marriage had presented at 3 months of age with BCG-osis, he also had Bocavirus infection and recurrent Streptococcal pneumonia. A homozygous mutation was identified in exon 2 of the ISG15 gene, c.454_455del, identified by NGS and confirmed by Sanger sequencing. The patient received ATT and antibiotics but succumbed to the disease.

\section{ROR $\gamma$ T Deficiency}

One patient (P26) was identified with ROR $\gamma \mathrm{T}$ deficiency caused due to homozygous mutation in Exon 5 of the RORC gene, c.558T $>$ G, identified by NGS and confirmed by Sanger sequencing by Dr. Anne Puel. The patient had presented with CNS tuberculomas, oral thrush, and onychomycosis. The patient received ATT and is currently well.

\section{Treatment and Outcome}

All patients were started on ATT comprising of a combination of four drugs -isoniazid, rifampicin, ethambutol, and pyrazinamide, which was altered based on sensitivity pattern. BCG strain was identified based on its inherent pyrazinamide resistance [Danish 1331 is pyrazinamide resistant (11)] hence in BCG-osis, pyrazinamide was not part of treatment protocol. Duration of treatment was 6 months to 2 years depending on the site of involvement. Eighty-five percent received one course of ATT, 7\% received two courses, $7 \%$ received three courses and $2 \%$ received five courses of ATT. Second-line drugs were given for a longer duration for MDR tuberculosis. Other antibiotics and antifungals based on drug sensitivity reports were added depending on concurrent infections. 6/51 (12\%) cases of molecularly confirmed MSMD underwent allogenic HSCT. Three patients of complete IL-12R $\beta 1$ (P32, P53, and P55) engrafted well and the patients are doing well. P32 and P53 had father as haploidentical donor while P55 had a fully matched sibling donor. One patient with complete IFN- $\gamma$ R1 (P54) underwent haploidentical HSCT as the child had no matched family donor, nor any matched unrelated donor. He rejected his graft and had autologous reconstitution by day 28 post-HSCT. He continues to be on four drug ATT. The siblings P51and P52 with complete IFN- $\gamma$ R2 deficiency underwent haplo-identical transplant from father; P51 is alive and well, while P52 expired 2 years later due to an unrelated cause. Three patients (P51, P52, and P53) were transplanted at Narayana Hrudayalaya, two (P54 and P55) at Apollo Chennai and One (P32) at CMC Vellore. Among 41 patients who could be followed $66 \%$ (27/41) are alive and well. Fourteen patients (34\%) expired of which four had IL-12R $\beta 1$ defect, two had AR complete IFN- $\gamma$ R1 deficiency, one had PD IFN- $\gamma$ R1 defect, four had AR complete IFN- $\gamma$ R2 defect, two AR complete STAT1 deficiency, and one AR ISG15 defect.

\section{DISCUSSION}

Although Inborn Errors of Immunity (IEI) as a group have been traditionally described to cause susceptibility to a wide range of micro-organisms, MSMD causes predisposition to infection by selective intracellular organisms. BCG related complications may be the presenting manifestation in MSMD in $4-80 \%$ of the patients (15). The practice of vaccinating all babies soon after birth might be the reason for an early presentation seen in our cohort; in addition to other well-known social factors like high population density, high incidence of $M$. $t b$ in the country, poor nutrition, and unhygienic conditions. Although the majority of our patients presented at $<3$ years of age, some patients presented later in life and their diagnosis was confirmed after several years. Like other inherited genetic IEI, MSMD too can present at any age and should be kept in the differential diagnosis of any child with the right clinical infection to suspect MSMD. This was observed in particular in two patients where the diagnosis was delayed for years before the infection gave a clue to MSMD. One child (P8) was diagnosed after a lymph node biopsy grew nontyphi Salmonella which was the clue to suspect MSMD and IL$12 \mathrm{R} \beta 1$ defect was confirmed. Another child (P7) with BCG-osis 
TABLE 2 | Molecular findings.

\begin{tabular}{|c|c|c|c|c|c|c|c|c|c|}
\hline Gene & Defect & $\begin{array}{l}\text { Number of } \\
\text { patients }\end{array}$ & Patient ID & Position & $\begin{array}{l}\text { Nucleotide } \\
\text { change }\end{array}$ & $\begin{array}{l}\text { Amino acid } \\
\text { change }\end{array}$ & Zygosity & Mutation type & Reported/novel \\
\hline \multirow[t]{8}{*}{$\mid L 12 R \beta 1$} & Complete & 1 & $\mathrm{P} 7$ & Exon 9 & c.982_982delC & p.M328Cfs*41 & Homozygous & Deletion & Novel \\
\hline & & 2 & P9, P25 & Exon 16 & c. $1786 A>G$ & p.K596E & Homozygous & Missense & $\begin{array}{l}\text { rs567051378 } \\
\text { (Reported } \\
\text { Benign in } \\
\text { Clinvar) }\end{array}$ \\
\hline & & 11 & $\begin{array}{l}\text { P10, P15, P19, } \\
\text { P28, P32, P34 } \\
\text { P39, P40, P41, } \\
\text { P46, P50 }\end{array}$ & Exon 9 & c. $962 \mathrm{C}>\mathrm{A}$ & p. $S 321^{*}$ & Homozygous & Nonsense & $\begin{array}{l}\text { rs147766868 } \\
\text { (PMID } \\
30255293)(17)\end{array}$ \\
\hline & & 6 & $\begin{array}{l}\text { P8, P16, P17, } \\
\text { P18, P45, P33 }\end{array}$ & Intron 15 & c. $1791+2 T>G$ & & Homozygous & $\begin{array}{l}\text { Essential } \\
\text { splicing site }\end{array}$ & $\begin{array}{l}\text { rs554063682 } \\
\text { (PMID } \\
26976630) \\
(17,18)\end{array}$ \\
\hline & & 2 & P36, P55 & Exon 7 & c.698_698delC & p.P233Lfs*9 & Homozygous & Deletion & Novel \\
\hline & & 1 & P14 & Exon 8 & c.599del & p.L200Rfs*3 & Homozygous & Deletion & $\begin{array}{l}\text { Novel } \\
\text { (rs1169002203) }\end{array}$ \\
\hline & & 1 & P49 & Intron 14 & c. $1738+2 \mathrm{~T}>\mathrm{A}$ & & Homozygous & $\begin{array}{l}\text { Essential } \\
\text { splicing site }\end{array}$ & Novel \\
\hline & & 1 & P53 & Exon 6 & c. $511 \mathrm{C}>\mathrm{T}$ & p.Q171* & Homozygous & Nonsense & Novel \\
\hline \multirow[t]{8}{*}{ IFNGR1 } & Partial & 4 & $\begin{array}{l}\text { P2, P11, P44, } \\
\text { P47 }\end{array}$ & Exon 6 & $\begin{array}{l}\text { c.818_821 } \\
\text { delTTAA }\end{array}$ & p.N274Hfs*2 & Heterozygous & Deletion & Novel \\
\hline & Complete & 1 & P12 & Exon 5 & c.601_601delC & p.Q201Sfs*2 & Homozygous & Deletion & Novel \\
\hline & & 1 & $\mathrm{P} 1$ & Exon 6 & c.838_839dupA & p.S280Kfs`3 & Homozygous & Duplication & Novel \\
\hline & & 1 & P48 & Exon 3 & c. $328 \mathrm{G}>\mathrm{T}$ & p.E110* & Homozygous & Nonsense & Novel \\
\hline & & 1 & P21 & Exon 4 & c. $389 \mathrm{C}>\mathrm{A}$ & p.P130H & Homozygous & Missense & Novel \\
\hline & & 1 & P35 & Exon 2 & c. $110 \mathrm{~T}>\mathrm{C}$ & p.137T & Homozygous & Missense & $\begin{array}{l}\text { rs945137618 } \\
\text { (PMID } \\
28744922)(19)\end{array}$ \\
\hline & & 1 & P31 & Exon 5 & c.653_655del & p.E218del & Homozygous & In-frame deletion & $\begin{array}{l}\text { rs587776858 } \\
\text { (PMID } \\
10811850)(20)\end{array}$ \\
\hline & & 1 & P54 & Exon 7 & c.1068delG & p.T357Lfs*15 & Homozygous & Deletion & Novel \\
\hline \multirow[t]{7}{*}{ IFNGR2 } & Complete & 1 & P6 & Exon 2 & c. $196 \mathrm{C}>\mathrm{T}$ & p.Q66* & Homozygous & Nonsense & Novel \\
\hline & & 1 & P20 & Intron 4 & c. $561+1 \mathrm{G}>\mathrm{A}$ & & Homozygous & $\begin{array}{l}\text { Essential } \\
\text { splicing site }\end{array}$ & Novel \\
\hline & & 1 & P24 & Exon 4 & c.540G $>A$ & p.W180* & Homozygous & Nonsense & Novel \\
\hline & & 1 & P29 & Exon 6 & $\begin{array}{l}\text { c.782_790del } \\
\text { TGCTGGCAG }\end{array}$ & p.V261_A263del & I Homozygous & In frame deletion & Novel \\
\hline & & 1 & P38 & Exon 4 & c. $488 \mathrm{~T}>\mathrm{C}$ & p.F163S & Homozygous & Missense & Novel \\
\hline & & 1 & P43 & Intron 3 & c. $412+2 \mathrm{~T}>\mathrm{A}$ & & Homozygous & $\begin{array}{l}\text { Essential } \\
\text { splicing site }\end{array}$ & Novel \\
\hline & & 2 & P51, P52 & Intron 2 & c. $207-1 \mathrm{G}>\mathrm{A}$ & & Homozygous & $\begin{array}{l}\text { Essential } \\
\text { splicing site }\end{array}$ & Novel \\
\hline ISG15 & Complete & 1 & P37 & Exon 2 & c.454_455delCT & p.L152Afs*? & Homozygous & Deletion & Novel \\
\hline \multirow[t]{3}{*}{ STAT1 } & Complete & 2 & P4, P5 & Exon 9 & c.769dup & p.D257Gfs`22 & Homozygous & Duplication & Novel \\
\hline & Partial & 1 & P30 & Exon 9 & c. $749 \mathrm{G}>\mathrm{A}$ & p.G250E & Heterozygous & Missense & Novel \\
\hline & & 1 & P42 & Intron 20 & c. $1728-4 \mathrm{C}>\mathrm{T}$ & & Heterozygous & $\begin{array}{l}\text { Essential } \\
\text { splicing site }\end{array}$ & $\begin{array}{l}\text { Novel } \\
\text { (rs760805208) }\end{array}$ \\
\hline IL12B & & 1 & P3 & Exon 4 & c. $429 \mathrm{G}>\mathrm{A}$ & p.W143* & Homozygous & Nonsense & $\begin{array}{l}\text { Novel } \\
\text { (rs751288779) }\end{array}$ \\
\hline$R O R C$ & Complete & 1 & P26 & Exon 5 & c. $558 \mathrm{~T}>\mathrm{G}$ & p.Y186* & Homozygous & Nonsense & Novel \\
\hline
\end{tabular}

* means termination; ? means unknown. 


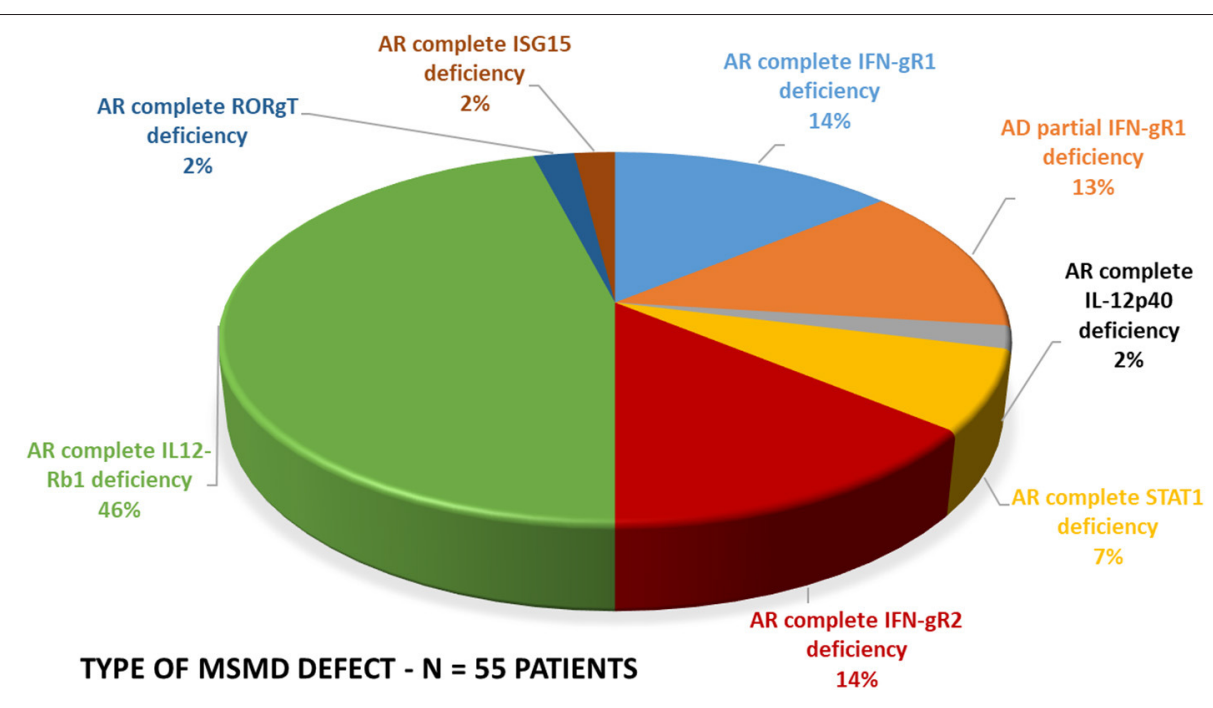

FIGURE 5 | Molecular defects. The molecular defects identified in our cohort were IL-12R $\beta 1$ (46\%) followed by complete IFN- $\gamma$ R1 (14\%), complete IFN- $\gamma$ R2 (14\%), PD-IFN- $\gamma$ R1 (13\%), complete STAT1 defect (7\%) and IL-12p40 defect (2\%), RORC(2\%), and ISG15(2\%).

after birth recovered and had two episodes of infection with Histoplasma; right shoulder osteomyelitis and later disseminated histoplasmosis. The clue to suspecting MSMD comes from knowing the organism. Local endemicity pattern for a particular infection (e.g., Leishmania donovani, Histoplasma capsulatum) may provide a difference in the pattern of infections in MSMD in different parts of the world. In India, Leishmania donovani is endemic in states of Bihar and Uttar Pradesh, however, we did not see a single case of MSMD with Leishmania donovani in our cohort while we did have cases of MSMD presenting with Histoplasmosis which is endemic in India.

Presence of mycobacterial infection in all patients suggests that the burden of exposure to Mycobacterium is very high in India. Isolation of NTM at a site other than the cervical node or wound site especially in the scenario of multifocal bone tuberculosis should initiate work up for underlying MSMD (23, 24). NTM was present in only $5 \%$ of our patients which is much less than what is reported in literature (25).

There is now a greater emphasis of making a definitive diagnosis of $M . t b$ in India and due to the availability of culture, GeneXpert, line probe assay, and NGS for mycobacterial genome, it is possible to make a correct microbiological diagnosis. In addition to accurately identifying the organism, the drug sensitivity pattern can help us treat our patients more appropriately and recognize multi-drug resistant (MDR) and extensively drug-resistant (XDR) tuberculosis.

Micro-organisms isolated can provide very important clues to underlying molecular defects. For instance, an association of Mycobacterial infection with CMV strongly suggests AR complete IFN $\gamma$ R1/R2 or AR complete STAT1 defect (26); with candidiasis suggests possibility of IL-12R $\beta 1$ defect or ROR $\gamma \mathrm{T}$ deficiency $(27,28)$; with Salmonella or non-typhi Salmonella strongly suggests the possibility of complete IL$12 \mathrm{R} \beta 1$ or IL-12p40 defect (29). Brain calcification along with mycobacterial infection suggests the possibility of ISG15 deficiency (30). Multifocal bone osteomyelitis by $M$. $t b$ or NTM strongly correlates with an underlying molecular defect of PD-IFN $\gamma$ R1 defect or PD-STAT1 defect (31). One can predict an underlying molecular defect based on the clinical presentation.

Complete IL-12R $\beta 1$ Deficiency caused by bi-allelic mutations in the IL12RB1 gene was the commonest underlying molecular defect identified in our cohort. Mutations resulting in premature stop codons, such as nonsense, and essential splicing-site mutations, represented the majority of IL-12R $\beta 1$ deficiency causing mutations (92\%). This defect is usually associated with a late presentation, however, in our cohort, the median age of presentation was earlier at 9 months due to mandatory BCG vaccination at birth. The high incidence of nonsense and essential splice site mutation could also contribute to earlier presentation. Almost $64 \%$ of patients had a single infection with MTBC, this finding is consistent with the finding reported previously in a survey of 141 IL-12R $\beta 1$ patients (32). It reflects the protective role of the primary infection against the reactivation of a latent organism or secondary infection. When compared to IFN $\gamma \mathrm{R} 1$ defects and STAT1 deficiency, IL-12R $\beta 1$ defect had a milder course of the disease which was observed by lower mortality $(16 \%$ in IL- $12 \mathrm{R} \beta 1$ compared to $20 \%$ in IFN $\gamma \mathrm{R} 1$, and $50 \%$ in STAT 1 defects altogether), fewer patients suffering from infections with multiple organisms, fewer courses of ATT required during the course of disease $(32,33)$. Although, the commonest mutation reported in literature is intron $15 \mathrm{c} .1791+2 \mathrm{~T}>\mathrm{G}$ (34), we found exon 9 c.962C $>$ A mutation to be the commonest in our cohort, which was present in almost half the patients. Multifocal bone tuberculosis may be seen in as much as half of the patients of PD IFN $\gamma \mathrm{R} 1$ deficiency (17). This is consistent with the finding in our cohort (57\%) with three patients having multifocal bone tuberculosis and one patient having joint involvement. 


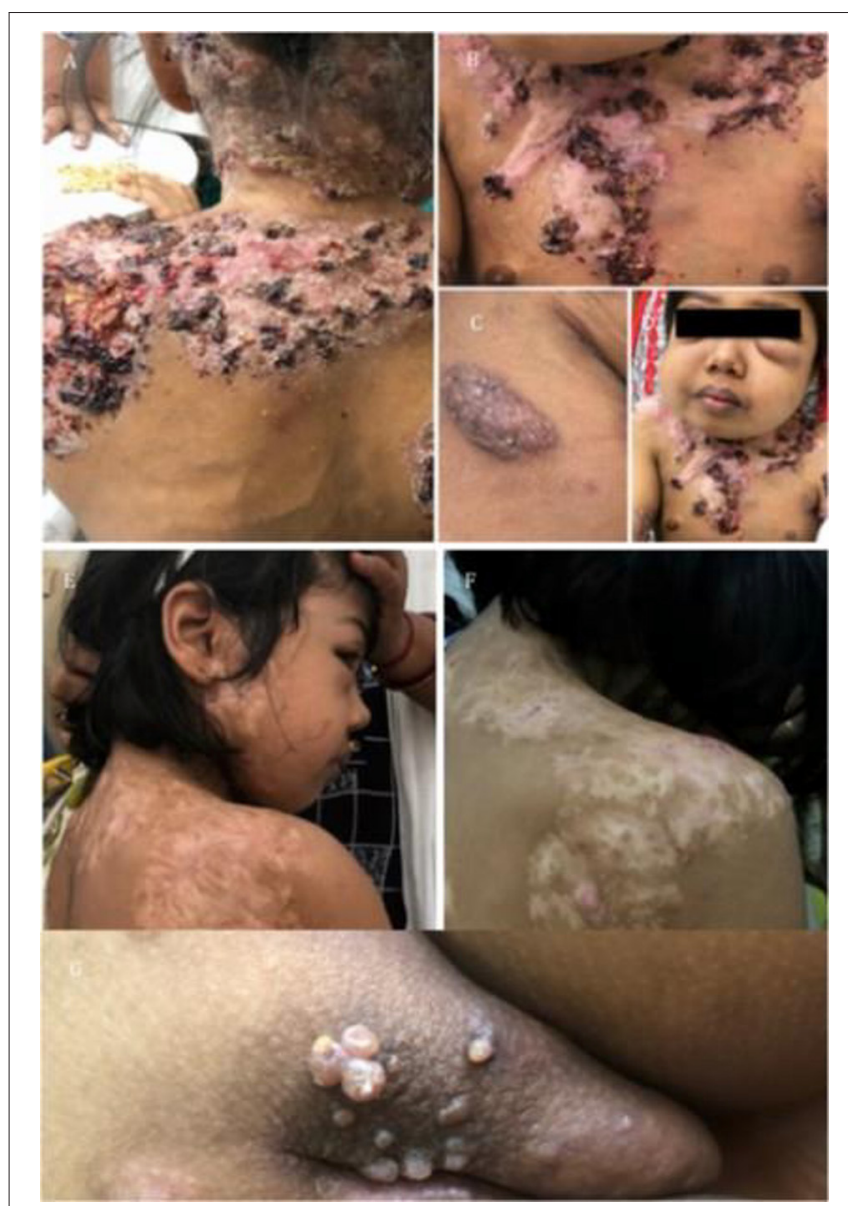

FIGURE 6 | Clinical images of a case with partial dominant IFN $\gamma R 1$ deficiency. (A-D) Severe cutaneous and bony MAC infection. (E,F) Response to AKT. (G) Development of Molluscum contagiosum.

STAT1 defects may also present with multifocal bone tuberculosis although this was not observed in our cohort.

Identification of a molecular defect can help us to take therapeutic management decisions. Patients with complete IFN$\gamma \mathrm{R} 1$, IFN $-\gamma \mathrm{R} 2$, and STAT1 deficiencies can be cured with HSCT (35). Majority of our patients were treated with 4 drug ATT as is the usual practice in our country, the duration of treatment ranging from 6 months to 2 years depending on the site of involvement and the clinical response to treatment. However, since most of the patients had BCG (Danish 1,331) disease, which is resistant to pyrazinamide, standard ATT was modified to include drugs according to the sensitivity pattern and more aggressive treatment was given for a longer duration. A few patients of IL-12R $\beta 1$ had a recurrence of infections and worsening of symptoms despite being on treatment. Such patients may benefit from treatment with IFN- $\gamma$ (36) which is currently not available in India. HSCT was performed in three patients (P33, P54, and P56) with IL-12R $\beta 1$ defect who are currently doing well.

This study describes the clinical and molecular spectrum of a large cohort of MSMD patients from India. It highlights the importance of having a high index of suspicion in patients presenting with adverse effects to BCG vaccination and investigating the IFN- $\gamma$ mediated immunity in all patients with a clinical suspicion of MSMD (21) irrespective of age. Flow cytometric evaluation is helpful in rapid diagnosis and provides important clues to the underlying genetic defect. It is also helpful for functional validation of novel genetic defects (37). With the increasing burden of MDR and XDR TB in India, awareness about MSMD will help clinicians to evaluate more patients for underlying genetic susceptibility to mycobacteria. Under the national TB program (RNTCP) microbiological confirmation is mandatory before initiation of ATT. With increasing awareness among physicians isolation of NTM/ EM while pursuing the microbiological diagnosis would prompt work up for underlying genetic defects. Knowledge of the underlying molecular defect is important not only in planning definitive therapy in the form of HSCT for severe forms of the disease but also providing genetic counseling to the affected families. Once a family member has been diagnosed with MSMD, BCG vaccination should be avoided in the next child until a genetic defect has been ruled out.

Tuberculosis still remains a major public health problem in India. With BCG vaccine given at birth and tuberculosis being endemic in India, diagnosing MSMD is critical not only for the appropriate management of the patient but also for the optimum control of tuberculosis. As seen in our cohort BCG-osis is the commonest presentation. We had high index of suspicion for BCG-osis in patients presenting with BCG adenitis, persistent AFB positivity, three episodes of MTB, strong family history of Koch, infections with Intracellular organisms like Non-typhi salmonella, Kala Azar, Histoplasma, and NTM. This has helped us in picking up cases of MSMD and instituting appropriate treatment including HSCT. This study also highlights the wide spectrum of micro-organisms seen with MSMD which is unique to our cohort. We also report higher prevalence of IFN $\gamma \mathrm{R} 2 \mathrm{defect}$ in India. Autoimmunity in MSMD has not been reported any literature, presence of multiple autoimmunity in our cohort of IL-12R $\beta 1$ requires further investigation and may indicate need for screening MSMD patients for autoimmune diseases. Flow cytometric analysis of MSMD is available at only two centers in our country this has limited functional validation in our cohort.

\section{DATA AVAILABILITY STATEMENT}

The original contributions presented in the study are included in the article/supplementary material, further inquiries can be directed to the corresponding author/s.

\section{ETHICS STATEMENT}

Ethical review and approval was not required for the study on human participants in accordance with the local legislation and institutional requirements. Written informed consent from the participants' legal guardian/next of kin was not required to participate in this study in accordance with the national legislation and the institutional requirements. Written informed consent was obtained from the minor(s)' legal guardian/next of 
kin for the publication of any potentially identifiable images or data included in this article.

\section{AUTHOR CONTRIBUTIONS}

$\mathrm{PT}, \mathrm{MD}$, and RY compiled the data, wrote, and edited the manuscript. VG, AAP, VVI, AC, ZG, SC, RA, PK, ND, BG, NF, EE, AA, AR, JD, VJ, RP, AJ, SuB, SaB, JU, NR, RR, RU, SP, HL, AA, MK, ZU, VB, and TK provided patient data and conducted clinical exploration and treatment of subjects. $\mathrm{AD}$, UB, and PMK did the flow work up of MSMD cases. JB, JC, and $\mathrm{AP}$ provided the molecular analysis. MD, MM, SSP, and MB supervised the study, reviewed, and approved the final version of the manuscript. All authors contributed to the article and approved the submitted version.

\section{ACKNOWLEDGMENTS}

We would like to acknowledge Dr. Zinet Currimbhoy who started the Immunology Department at B. J. Wadia Hospital for

\section{REFERENCES}

1. Rosain J, Kong X, Martinez-Barricarte R, Oleaga-Quintas C, Ramirez-Alejo N, Markle J, et al. Mendelian susceptibility to mycobacterial disease: 2014-2018 update. Immunol Cell Biol. (2019) 97:360-7. doi: 10.1111/imcb.12210

2. Casanova J-L, Abel L. Genetic dissection of immunity to mycobacteria: the human model. Annu Rev Immunol. (2002) 20:581-620. doi: 10.1146/annurev.immunol.20.081501.125851

3. Tangye SG, Al-Herz W, Bousfiha A, Chatila T, CunninghamRundles C, Etzioni A, et al. Human inborn errors of immunity: 2019 update on the classification from the International Union of Immunological Societies Expert Committee. J Clin Immunol. (2020) 40:24-64. doi: 10.1007/s10875-019-00737-x

4. MacLennan C, Fieschi C, Lammas DA, Picard C, Dorman SE, Sanal $\mathrm{O}$, et al. Interleukin (IL)-12 and IL-23 are key cytokines for immunity against Salmonella in humans. J Infect Dis. (2004) 190:1755-7. doi: 10.1086/ 425021

5. Wu UI, Holland SM. A genetic perspective on granulomatous diseases with an emphasis on mycobacterial infections. Semin Immunopathol. (2016) 38:199212. doi: 10.1007/s00281-015-0552-y

6. Ouederni M, Sanal O, Ikinciogullari A, Tezcan I, Dogu F, Sologuren $\mathrm{I}$, et al. Clinical features of candidiasis in patients with inherited interleukin 12 receptor $\beta 1$ deficiency. Clin Infect Dis. (2014) 58:20413. doi: $10.1093 / \mathrm{cid} / \mathrm{cit} 722$

7. León-Lara X, Hernández-Nieto L, Zamora CV, Rodríguez-D’Cid R, Gutiérrez MEC, Espinosa-Padilla S, et al. Disseminated infectious disease caused by histoplasma capsulatum in an adult patient as first manifestation of inherited IL-12R $\beta 1$ deficiency. J Clin Immunol. (2020) 40:10514. doi: 10.1007/s10875-020-00828-0

8. Parvaneh N, Barlogis V, Alborzi A, Deswarte C, Boisson-Dupuis S, Migaud M, Farnaria C, et al. Visceral leishmaniasis in two patients with IL-12p40 and IL-12R $\beta 1$ deficiencies. Pediatr Blood Cancer. (2017) 64:e26362. doi: 10.1002/pbc.26362

9. Dorman SE, Uzel G, Roesler J, Bradley JS, Bastian J, Billman G, et al. Viral infections in interferon- $\gamma$ receptor deficiency. J Pediatr. (1999) 135:6403. doi: 10.1016/S0022-3476(99)70064-8

10. Ministry of Health \& family Welfare, Central Tuberculosis Division Government of India. National Tuberculosis elimination Programme Annual Report [Internet]. New Delhi: Government of India (2020). Available online at: https://tbcindia.gov.in/showfile.php?lid=3538
Children in early 2000s and continues to support and mentor the department. We thankfully acknowledge Foundation for Primary Immunodeficiencies, USA for providing a platform to collate and present the data regarding MSMD in India. We acknowledge Indian Council of Medical Research (ICMR), New Delhi, India for funding the Centre of Excellence in PID (vide Grant No. 61/02/2012/IMM/BMS) which supports the diagnostic workup of the cases. However, the funders had no role in study design, data collection and analysis, decision to publish, or preparation of the manuscript. We would also like to thank Dr. Dinakantha Kumararatne, Cambridge University, who helped us with the diagnosis of our first case of IL12RB1 defect. The Laboratory of Human Genetics of Infectious Diseases is supported in part by institutional grants from INSERM, University of Paris, The Rockefeller University and the St. Giles Foundation, the National Institute of Allergy and Infectious Diseases (NIAID) of the National Institutes of Health (NIH) (R37AI095983 for JLC), and grants from the French National Research Agency (GENMSMD, ANR-16-CE17-0005-01 for JB, and ANR GENCMCD, ANR-11BSV3-005-01 for AP). $\begin{array}{lcllr}\text { 11. World } & \text { Health } & \text { Organization. BCG } & \text { vaccine: } & \text { WHO } \\ \text { position } & \text { paper, } & \text { February } 2018 & \text { recommendations. } \\ \text { Vaccine. } & (2018) & 36, \quad 3408-10 . \quad \text { doi: } & 10.1016 / \text { j.vaccine.2018. }\end{array}$ 03.009

12. Bandari AK, Muthusamy B, Bhat S, Govindaraj P, Rajagopalan P, Dalvi A, et al. A novel splice site mutation in IFNGR2 in patients with primary immunodeficiency exhibiting susceptibility to mycobacterial diseases. Front Immunol. (2019) 10:1964. doi: 10.3389/fimmu.2019.01964

13. Merchant RH, Ahmed J, Ahmad N. XDR TB in a case of IL12R $\beta 1$ deficiency: a case report of mendelian susceptibility to mycobacterial disease from India. Indian J Pediatr. (2013) 80:781-2. doi: 10.1007/s12098-012-0806-9

14. Sharma VK, Pai G, Deswarte C, Lodha R, Singh S, Kang LW, et al Disseminated Mycobacterium avium complex infection in a child with partial dominant interferon gamma receptor 1 deficiency in India. J Clin Immunol. (2015) 35:459-62. doi: 10.1007/s10875-015-0173-1

15. Indumathi CK, Kowtal PM, Poornima RN, Lewin S. Clinical profile and outcome of clinical BCG disease in infants. Indian Pediatr. (2014) 51:730 2. doi: 10.1007/s13312-014-0491-Z

16. Bernatowska EA, Wolska-Kusnierz B, Pac M, Kurenko-Deptuch M, Zwolska Z, Casanova J-L, et al. Disseminated bacillus CalmetteGuérin infection and immunodeficiency. Emerg Infect Dis. (2007) 13:799. doi: 10.3201/eid1305.060865

17. Nekooie-Marnany N, Deswarte C, Ostadi V, Bagherpour B, Taleby E, Ganjalikhani-Hakemi $M$, et al. Impaired IL-12- and IL-23-mediated immunity due to IL-12R $\beta 1$ deficiency in Iranian patients with mendelian susceptibility to mycobacterial disease. J Clin Immunol. (2018) 38:78793. doi: 10.1007/s10875-018-0548-1

18. Lim AI, Menegatti S, Bustamante J, Le Bourhis L, Allez M, Rogge L, et al. IL12 drives functional plasticity of human group 2 innate lymphoid cells. J Exp Med. (2016) 213:569-83. doi: 10.1084/jem.20151750

19. van de Vosse E, van Dissel JT. IFN- $\gamma \mathrm{R} 1$ defects: mutation update and description of the IFNGR1 variation database. Hum Mutat. (2017) 38:128696. doi: 10.1002/humu.23302

20. Jouanguy E, Dupuis S, Pallier A, Döffinger R, Fondanèche MC, Fieschi C, et al In a novel form of IFN- $\gamma$ receptor 1 deficiency, cell surface receptors fail to bind IFN- $\gamma$. J Clin Invest. (2000) 105:1429-36. doi: 10.1172/JCI9166

21. Bustamante J, Boisson-Dupuis S, Abel L, Casanova J-L. Mendelian susceptibility to mycobacterial disease: Genetic, immunological, and clinical features of inborn errors of IFN- $\gamma$ immunity. Semin Immunol. (2014) 26, 454-70. doi: 10.1016/j.smim.2014.09.008 
22. BustamanteJ. Mendelian susceptibility to mycobacterial disease: recent discoveries. Hum Genet. (2020) 139:9931000. doi: 10.1007/s00439-020-02120-y

23. Mandell DL, Wald ER, Michaels MG, Dohar JE. Management of nontuberculous mycobacterial cervical lymphadenitis. Arch Otolaryngol Neck Surg. (2003) 129:341-4. doi: 10.1001/archotol.129.3.341

24. Lake MA, Ambrose LR, Lipman MCI, Lowe DM. "Why me, why now?" Using clinical immunology and epidemiology to explain who gets nontuberculous mycobacterial infection. BMC Med. (2016) 14:113. doi: 10.1186/s12916-016-0606-6

25. Ratnatunga CN, Lutzky VP, Kupz A, Doolan DL, Reid DW, Field M, et al. The rise of non-tuberculosis mycobacterial lung disease. Front Immunol. (2020) 11:303. doi: 10.3389/fimmu.2020.00303

26. Casanova JL, Ochs HD. Interferon- $\gamma$ receptor deficiency: an expanding clinical phenotype? J Pediatr. (1999) 135:5435. doi: 10.1016/S0022-3476(99)70050-8

27. Okada S, Markle JG, Deenick EK, Mele F, Averbuch D, Lagos M, et al. Impairment of immunity to Candida and Mycobacterium in humans with bi-allelic RORC mutations. Science. (2015) 349:606-13. doi: 10.1126/science.aaa4282

28. De Beaucoudtey L, Puel A, Filipe-Santos O, Cobat A, Ghandil P, Chrabieh M, et al. Mutations in STAT3 and IL12RB1 impair the development of human IL-17-producing T cells. J Exp Med. (2008) 205:154350. doi: $10.1084 /$ jem.20080321

29. Tan Ç, Çagdaş-Ayvaz D, Metin A, Keskin Ö, Tezcan I, Sanal Ö. Clinical and genetic features of IL12R $\beta 1$ deficiency: single center experience of 18 patients. Turk J Pediatr. (2016) 58:356-61. doi: 10.24953/turkjped.2016.04.002

30. Zhang X, Bogunovic D, Payelle-Brogard B, Francois-Newton V, Speer SD, Yuan C, et al. Human intracellular ISG15 prevents interferon$\alpha / \beta$ over-amplification and auto-inflammation. Nature. (2015) 517:8993. doi: 10.1038/nature13801

31. Nishimura S, Tsumura M, Hirata O, Kagawa R, Mizoguchi Y, Okada $\mathrm{S}$, et al. MSMD patients with IFN-g-STAT1 signaling defect present enhanced osteoclastogenesis and bone resorption. Blood. (2015) 126:3591. doi: 10.1182/blood.V126.23.3591.3591

32. De Beaucoudrey L, Samarina A, Bustamante J, Cobat A, BoissonDupuis S, Feinberg J, et al. Revisiting human IL-12R $\beta 1$ deficiency: a survey of 141 patients from 30 countries. Medicine. (2010) 89:381. doi: 10.1097/MD.0b013e3181fdd 832
33. Fieschi C, Dupuis S, Catherinot E, Feinberg J, Bustamante J, Breiman A, et al. Low penetrance, broad resistance, and favorable outcome of interleukin 12 receptor $\beta 1$ deficiency: Medical and immunological implications. J Exp Med. (2003) 197:527-35. doi: 10.1084/jem.20021769

34. van de Vosse E, Haverkamp MH, Ramirez-Alejo N, Martinez-Gallo M, Blancas-Galicia L, Metin A, et al. IL-12R $\beta 1$ deficiency: mutation update and description of the IL12RB1 variation database. Hum Mutat. (2013) 34:132939. doi: 10.1002/humu. 22380

35. Tovo P-A, Garazzino S, Saglio F, Scolfaro C, Bustamante J, Badolato $\mathrm{R}$, et al. Successful hematopoietic stem cell transplantation in a patient with complete IFN- $\gamma$ receptor 2 deficiency: a case report and literature review. J Clin Immunol. (2020) 40:1191-5. doi: 10.1007/s10875-02000855-x

36. Bax HI, Freeman AF, Ding L, Hsu AP, Marciano B, Kristosturyan $\mathrm{E}$, et al. Interferon alpha treatment of patients with impaired interferon gamma signaling. J Clin Immunol. (2013) 33:9911001. doi: 10.1007/s10875-013-9882-5

37. Esteve-Solé A, Sologuren I, Martínez-Saavedra MT, Deyà-Martínez À, Oleaga-Quintas C, Martinez-Barricarte R, et al. Laboratory evaluation of the IFN- $\gamma$ circuit for the molecular diagnosis of Mendelian susceptibility to mycobacterial disease. Crit Rev Clin Lab Sci. (2018) 55:184-204. doi: 10.1080/10408363.2018.144 4580

Conflict of Interest: The authors declare that the research was conducted in the absence of any commercial or financial relationships that could be construed as a potential conflict of interest.

Copyright (C) 2021 Taur, Gowri, Pandrowala, Iyengar, Chougule, Golwala, Chandak, Agarwal, Keni, Dighe, Bodhanwala, Prabhu, George, Fouzia, Edison, Arunachalam, Madkaikar, Dalvi, Yadav, Bargir, Kambli, Rawat, Das, Joshi, Pilania, Jindal, Bhat, Bhattad, Unni, Radhakrishnan, Raj, Uppuluri, Patel, Lashkari, Aggarwal, Kalra, Udwadia, Bafna, Kanade, Puel, Bustamante, Casanova and Desai. This is an openaccess article distributed under the terms of the Creative Commons Attribution License (CC BY). The use, distribution or reproduction in other forums is permitted, provided the original author(s) and the copyright owner(s) are credited and that the original publication in this journal is cited, in accordance with accepted academic practice. No use, distribution or reproduction is permitted which does not comply with these terms. 